\title{
Algunas claves investigativas en el estudio del mundo popular. Conversaciones con Alejandro Moreno Olmedo y Philippe Bourgois
}

\author{
José Antonio Matos Contreras
}

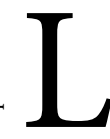
as siguientes entrevistas conversacionales fueron realizadas en distintos momentos. La conversación con Alejandro Moreno, religioso salesiano, sacerdote, psicólogo, doctor en ciencias sociales, miembro fundador y director del Centro de Investigaciones Populares (CIP), tuvo lugar hace año y medio aproximadamente. Moreno y el cIP son reconocidos por la pertinencia de sus trabajos enfocados al "conocimiento comprensivo del mundo-de-vida-popular venezolano". Las investigaciones realizadas por el autor de El aro y la trama y el CIP se inscriben en el vasto paradigma de los métodos cualitativos de investigación social, en especial en el "enfoque biográfico" o "historias de vida". ${ }^{1} \mathrm{El}$ más reciente trabajo del cIP es sobre el "delincuente venezolano violento de origen popular", obra voluminosa que deja abiertas para cualquier interesado numerosas interrogantes.

${ }^{1}$ Moreno reconoce ubicarse inicialmente en la "investigaciónacción", pero en un sentido no clásico. Véase el desarrollo de su entrevista.

\begin{abstract}
El encuentro con Philippe Bourgois tuvo lugar durante las Jornadas de Investigación Reconfiguraciones del Mundo Popular, llevadas a cabo en gran parte en la Universidad Central de Venezuela del 16 al 20 de julio de 2012. En el marco de ese evento conversé con el antropólogo estadounidense, quien tiene una extensa trayectoria en investigaciones de campo. En sus comienzos trabajó en Centroamérica, en Mosquitia - Honduras-Nicaragua-, en Panamá, Costa Rica —en 1981 y 1984- y en El Salvador. De 1985 a 1991 exploró desde dentro el barrio East Harlem, la segregación étnica y la marginación económica de ciudadanos afroestadounidenses y latinos, cuyo resultado fue En busca de respeto: vendiendo crack en Harlem, en la actualidad una referencia imprescindible de los estudios etnográficos urbanos. Posteriormente investigó sobre la violencia de las pandillas y de los jornaleros indocumentados en San Francisco. Con la sensibilidad social que lo caracteriza, realizó Righteous Dopefiend (2009b), donde documenta historias de vida y estrategias de supervivencia de adictos a la heroína y al crack.
\end{abstract} 189

Some Investigation Keys on Studies about Lower Social Classes.

Talking with Alejandro Moreno Olmedo and Philippe Bourgois

José Antonio Matos Contreras: Universidad Bolivariana de Venezuela, Caracas, Venezuela jmatos007@hotmail.com

Desacatos, núm. 41, enero-abril 2013, pp. 189-197 
Busca analizar la lógica de su mundo de vida y "las fuerzas estructurales" que inciden en su destrucción.

Es relevante destacar que ambos autores, aunque puedan tener diferencias epistemológicas, coinciden principalmente en la importancia que tienen la implicación o "implicancia" (Moreno) y el compromiso ético hacia las personas y comunidades en las que desarrollan sus estudios.

\section{CONVERSACIÓN CON ALEJANDRO MORENO OLMEDO: "MI INTERÉS ES EL MUNDO POPULAR EN RELACIÓN”}

José Antonio Matos Contreras (JAMC): ¿Sus estudios tienen alguna vinculación con la investigaciónacción como señalaba en $\mathrm{El}$ aro y la trama?

Alejandro Moreno Olmedo (АMo): Eso aparece muy claro en esa obra en la página 20 [busca el libro y lee]: "Pienso que si se quiere darle un nombre a este estudio..." [detiene la lectura]. Eso está pensalo haga [continúa la lectura del párrafo] "habría que ubicarlo de alguna manera en lo que hoy [reitera que es en 1993] se conoce como 'investigaciónacción"'. Globalmente pudiera entrar allí, pero en un sentido más radical del que tiene el término en la literatura actual [sigue la lectura]. "En mi caso, la investigación surge de la vida más que de la acción pura y en ningún momento fue pensada y planificada como tal. Se dio como una exigencia”.

JAMC: Es decir, ¿no tiene un énfasis metodológico a priori?

Aм0: No, no, eso se produce. Esto es a mi entender lo que otorga un valor e importancia a la investigación-acción, ya que es la resultante de una exigencia de investigación que se centra en la vida de la gente. Al centrar una investigación en la vida de la gente, tienes que convivir y hacer. Por ese motivo es

${ }^{2}$ Consulta la tercera edición. En la edición actual de Convivium Press (2008a) sería la página 22.

más radical que la investigación-acción clásica, en la cual prevalece una intención política por parte de los investigadores. Aunque no quiere decir que la investigación-acción que realizo no sea política. ¡Cuidado! Pero no va con una intención política, va con una intención de vida, lo cual no descarta que concluya con una intencionalidad política.

En la obra El presidente Nieto: historia doble de la costa (tomo 2) de Fals Borda (2002), en una página está cómo el campesino cuenta las cosas y en la otra cómo se interpretan marxistamente esas cosas. ${ }^{3}$ Aunque posteriormente Fals Borda cambiara. Así era como se entendía la investigación-acción. Es decir, estaba encuadrada en una doctrina previamente establecida. No es que a partir de la investigación se llegue a tal teoría, sino que era previa a la propia investigación. En eso es que no estoy de acuerdo, se puede llegar a eso o algo más importante o distinto a partir de la investigación. Entonces en la obra de Fals Borda por una parte está la narración del campesino que es "ingenua", y por otra la interpretación del investigador que es "científica". Ése era el planteamiento de Fals Borda en aquel momento, él modificó sus planteamientos después y reconoce que es un sesgo indebido.

JAMC: En escritos como Sociología e investigaciónacción participativa ${ }^{4}$ Fals Borda afirma que existen avances teóricos-prácticos durante más de 30 años de su aplicación y estudio. Además, enfatiza el uso de una conceptualización adecuada y propia a las realidades estudiadas y la necesidad de privilegiar la "suma de saberes" en la investigación-acción participativa.

AMo: Claro, pero en 1993 todavía predominaba esa visión doctrinal de la investigación-acción. Por eso intento separarme de ese enfoque en aquel momento.

\footnotetext{
${ }^{3}$ En la presentación de la obra en la edición colombiana de Ancora Editores, Gustavo Bell Lemus (2002) señaló algunas críticas a la obra: "Varios historiadores se han referido al excesivo simplismo del libro en el tratamiento de ciertos temas, y otros han criticado la manifiesta voluntad del autor de escribir un texto políticamente comprometido".

${ }^{4}$ Véase capítulo IV (Fals Borda, 2002b).
} 
JAMC: También busca diferenciarse de otros autores contemporáneos europeos, como Michel Maffesoli y Michel Foucault a nivel epistemológico. ¿Podrías hablarnos de eso?

AMO: Me diferencio principalmente de autores como Foucault y Maffesoli en el aspecto de la episteme de la que ellos parten. El trasfondo de esos autores es que piensan lo colectivo a través del individuo. En mi caso, no hablo de individuo y colectivo. Eso pertenece a otro mundo de vida. Mi interés es el mundo de la vida popular en relación, en el cual no cabe el concepto de individuo y colectivo. En tal mundo relacional entra el concepto de persona y comunidad. Entonces ésa es la diferencia, hay una tradición occidental moderna que utiliza como eje el concepto de "individuo" y "colectivo". Incluso los posmodernos están en la modernidad. Tienen las mismas reglas del pensamiento de la episteme moderna.

JAMC: En las investigaciones realizadas por usted y el Centro de Investigaciones Populares sobre el mundo relacional propio de la vida popular ¿han estudiado la religiosidad popular?

AMO: No propiamente, aunque hemos encontrado en las historias de vida manifestaciones de religiosidad popular. Tal es el caso de la historia de Felicia Valera. Es el único trabajo en el que abordamos la religiosidad porque sale de su historia [busca el libro en su biblioteca]. Hay un capítulo titulado "La religiosidad popular en la historia de Felicia Valera", específicamente en esa mujer de procedencia popular. En otros trabajos, como en las investigaciones sobre el delincuente venezolano violento de origen popular ${ }^{5}$ encontramos en los malandros un tipo de religiosidad. Los malandros estudiados creen en Dios, pero Dios es esencialmente un cómplice, se convierte en protector al cual se manipula o se maneja por conveniencia propia. Entonces es una relación mágico-religiosa. Dios es una fuerza superior que se busca manipular para que me obedezca a mí. Aunque esto resulta muy complejo.

\footnotetext{
${ }^{5}$ Véase Moreno et al. (2009).
}

JAMC: En esa investigación la noción de "vía" resulta muy interesante. ¿Tiene esta noción algo que ver con lo religioso?

AMO: La "vía" no es propiamente religiosa. Aunque hay en el fondo una fuerza superior que obliga a seguirla, pero los malandros no lo disciernen de esa manera. Piensan que una vez que se han metido en la "vía", ésta actúa por su cuenta. La "vía" no es una fuerza sobrenatural. Es una condición de lo que uno no sale. Al meterte en aquello, no puedes salir. No existe libertad, ya que no se puede salir de eso.

JAMC: Podría tener una analogía con el enganchado a la adicción de las drogas, en la que el deseo de "descolgarse" de toda afección, ocupación o preocupación se encuentra "colgado" de una sola cosa. ${ }^{6}$

Aм0: Sí, eso puede servir como imagen o metáfora para poder entender lo que queremos decir con la "vía".

JAMC: En las historias de algunos delincuentes ¿han encontrado algún remordimiento o culpa por sus acciones?

АMо: En el caso de los delincuentes viejos existe lo que pudiera entenderse como la conciencia de que han hecho un daño. En los jóvenes no hemos encontrado ningún sentimiento de culpa o remordimiento. En el primer tomo se encuentra algo en el viejo José y en Alfredo, de edad mediana, que manifiesta un sentimiento de culpa, por lo menos de defenderse de una conducta mala: “¡Yo no lo hice!”, cuestión contraria a los jóvenes, que afirman sus acciones delictivas.

JAMC: ¿Hay en esos jóvenes una especie de desarraigo?

AMO: Sí, total. El joven es más simple. Tiene una personalidad simple en el sentido de falta de complejidad en sus ideas y actitudes.

JAMC: ¿Podría hablarse de que ejercen una actitud de negación respecto de la mayoría de sus acciones y sentimientos?

\footnotetext{
${ }^{6}$ Véase Sissa (2000).
} 
AMо: Si realizas un análisis psicoanalítico, podría hablarse de negación. Pero nosotros tratamos de evitar la interpretación teórica a partir de escuelas. Aunque el psicoanalista está en todo su derecho de interpretarlo de esa manera, nuestro interés es buscar la forma más antropológica y de más utilidad para todos. De manera que cualquiera pueda aplicar su propia interpretación. Es decir, que pueda elaborarlo y desarrollarlo de acuerdo con la adscripción que tenga a una teoría psicológica, sociológica o antropológica.

JAMC: Ustedes plantean que es muy difícil significar la violencia actual. En el perfil del delincuente violento popular, del volumen II, afirman: "La sociedad, la cultura, todavía no ha elaborado dispositivos adecuados para delimitarla y representársela, para significarla".

AMO: Esto es sorprendente, tanto que la califican como "loca". Con eso no se dice nada. Es decir, que es incomprensible, no se tiene cómo representarla. ¡Es loca! No tiene lógica. No existe un esquema mental para analizarla. Entonces se recurre al esquema mental más amplio que es la locura. Todavía no se ha logrado, es lo que yo digo, no se encuentra en la literatura y en la gente. Es decir, en la sociedad, entendiéndola por el común de la población y las instituciones sociales, no tienen cómo enfocarla de una manera esquemática y representativa.

JAMC: Esto es muy interesante, ya que deja abierta una tesis para desarrollar. Ahora bien, ¿cree que pudiera haber distintos ámbitos de lo social que intenten significarla, como es el caso de la expresión mágicoreligiosa de la Corte Malandra perteneciente al culto de María Lionza?

Aм0: Sí, sí, claro. La dificultad de significarla es que la violencia tiene sentidos muy variados. No es la violencia, son las violencias. Por ejemplo, aquellos que otorgan un sentido mágico-religioso, como

${ }^{7}$ Véase Moreno et al. (2009, II: 863).

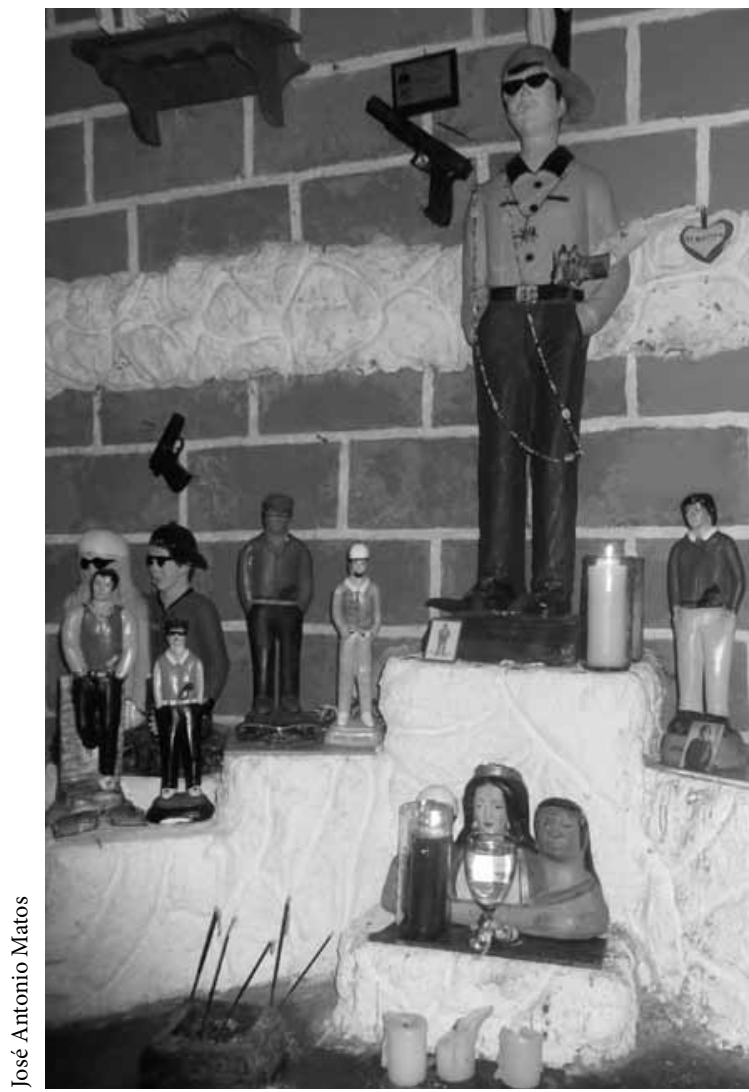

La Corte Malandra. Esta expresión religiosa del espiritismo marialioncero tiene como característica deificar delincuentes de las décadas de 1960 y 1970 que tenían códigos sociales de convivencia y una ética delincuencial, 2012.

la Corte Malandra, sería un grupo que permitiría pensarla a partir de esos términos. Pero otros que no tuvieran ahí, tendrían que pensarla con otros esquemas.

JAMC: Nos encontramos en lo que ha llamado un "proceso de progresiva autonomización de la violencia". ${ }^{8}$

AMO: Sí y eso es hoy un dramático problema social. De ahí la necesidad de buscar cómo comprender su lógica interna.

\footnotetext{
${ }^{8}$ Véase Moreno (2008b).
} 
CONVERSACIÓN CON PHILIPPE BOURGOIS: "PRACTICAR UNA GENEROSIDAD HERMENÉUTICA A LOS SUJETOS EN LA INVESTIGACIÓN"

José Antonio Matos Contreras (JAMC): ¿Qué aspectos consideras relevantes en la etnografía que realizas en los barrios?

Philippe Bourgois (PB): Considero importante mantener una larga trayectoria de vinculación con los sujetos y amigos en las investigaciones que realizo. Eso representa una ética personal y un poco de sentido común, ya que resulta un sinsentido llegar ahí, hacer tu trabajo y nunca compartir nada con la gente. También es algo afectivo, debido a que construyes amistades con algunos. En el caso particular de En busca de respeto..., Primo ${ }^{9}$ vino a ser un buen amigo a través de los años. Lo veo cuando voy a Nueva York y nos comunicamos continuamente por teléfono.

Por otra parte, desde el punto de vista científico y metodológico proporciona una visión a largo plazo que es realmente útil para comprender cómo las fuerzas estructurales, las instituciones y los cambios en determinadas circunstancias históricas afectan la vida de las personas. Al observar unos 20 años en la vida de Primo se pueden mostrar los efectos de las cárceles, los cambios de leyes del bienestar social, procesos sobre los cuales las instituciones inciden en el barrio, los cambios de parentesco, los procesos reflexivos personales, entre otros aspectos. De manera que permiten analizar los cambios estructurales. En la etnografía de larga trayectoria resulta menos difícil visualizar esos aspectos estructurales, lo que resulta más problemático y difícil en una de corto plazo. Es curioso porque no lo había pensado cuando inicié el trabajo. Fue algo natural, hice amistad y conservé los contactos. Comprobé que eso representa

\footnotetext{
${ }^{9}$ Primo, con César y Candy, son los interlocutores más emblemáticos de En busca de respeto: vendiendo crack en Harlem. Una muestra de la trayectoria de amistad de Primo y Philippe es el "Epílogo" a la versión en español (Burgois, 2010).
}

algo valioso para vincular la etnografía con el estudio de las fuerzas estructurales e históricas.

JAMC: Esto tiene sentido con la afirmación que hacías en la "Introducción" de En busca de respeto..., que la cualidad principal de la metodología etnográfica es que permite el surgimiento de los "peones de las fuerzas estructurales". ${ }^{10}$ Es decir, ¿la etnografía de larga trayectoria permite observar cómo determinadas estructuras sociales inciden en los sujetos?

PB: Sí, y eso es lo difícil de ver, porque en la etnografía, al estar en un contacto diario, es muy fácil caer en una visión de telenovela, debido a que todo puede ser muy dramático. Entonces, puede ocurrir que el investigador, al estar sumergido en las patologías, las bondades y otros caracteres de los sujetos, pierda de vista los efectos estructurales de la historia y el poder. Por eso es importante realizar el trabajo etnográfico de forma consciente y teóricamente pertinente en la medida en que realizas el trabajo de campo. Se trata de pensar cómo puedo organizar más observaciones sobre lo que realiza la gente y empujar las conversaciones para que surjan elementos de mi interés, como el racismo, el desempleo, la violencia familiar o determinado tema. Eso es algo que requiere analizarse durante el trabajo de campo, ya que al estar únicamente en la interacción se corre el riesgo de perderse en el bosque por la maleza de los árboles y olvidar la estructura del bosque.

JAMC: ¿Compartes con James Clifford el pensar el trabajo de campo en la investigación etnográfica antropológica como un habitus? ${ }^{11}$

PB: Estoy de acuerdo con James Clifford en que ser antropólogo, etnógrafo o realizar la práctica de la etnografía, aunque no sea antropólogo, es un habitus. Esto es interesante porque nuestra disciplina

\footnotetext{
${ }^{10}$ Véase Bourgois (2010: 47).

${ }^{11}$ Véase Clifford (2008), en especial el capítulo III, "Prácticas espaciales: el trabajo de campo, el viaje y la disciplina de la antropología", en el que dice: "Un campo por definición no está invadido por la maleza” (Clifford, 2008: 72). En el apartado 3 señala que resulta útil pensar el campo como un habitus.
} 
de la antropología lo enseña muy mal. Es decir, esa metodología en la antropología es enseñada mediante la lectura de muchas etnografías. A través de las lecturas es que intuitivamente se aprende cómo hacerlo. Esto resulta insuficiente, deberíamos obligarnos a enseñar más la metodología por más que resulte aburrida [pausa]. También es importante destacar que no hay una única receta, porque es esencialmente una sensibilidad. En tal sentido, James Clifford está en lo cierto al afirmar que es un habitus. Se trata ante todo de estar abierto al relativismo cultural, al respeto por los sujetos, lo que llamo una "generosidad hermenéutica a los sujetos en la investigación”. Además, es pertinente una autocrítica constante que se traduzca en una falta de confianza a sí mismo y a su propia subjetividad. Hay que considerar que uno está viendo lo que quiere ver. Está observando, lo que es un prejuicio teórico, político, o haciendo un juicio moral. Por eso hay que preguntarse continuamente: ¿Qué estoy viendo? ¿Qué prejuicios estoy imaginando sobre mis observaciones e interacciones y sobre la forma en que llevo o conduzco las entrevistas conversacionales?

JAMC: Decías en una de las conferencias que la etnografía tiene algo de terapia.

PB: Sí, en especial a nivel personal, al realizar mis trabajos en situaciones donde la gente vive con mucho sufrimiento, violencia y miseria. Estos aspectos son deprimentes y producen muchas emociones, en especial tristeza y miedo. Además, uno siente culpa de ser un antropólogo debido a que tiene el privilegio

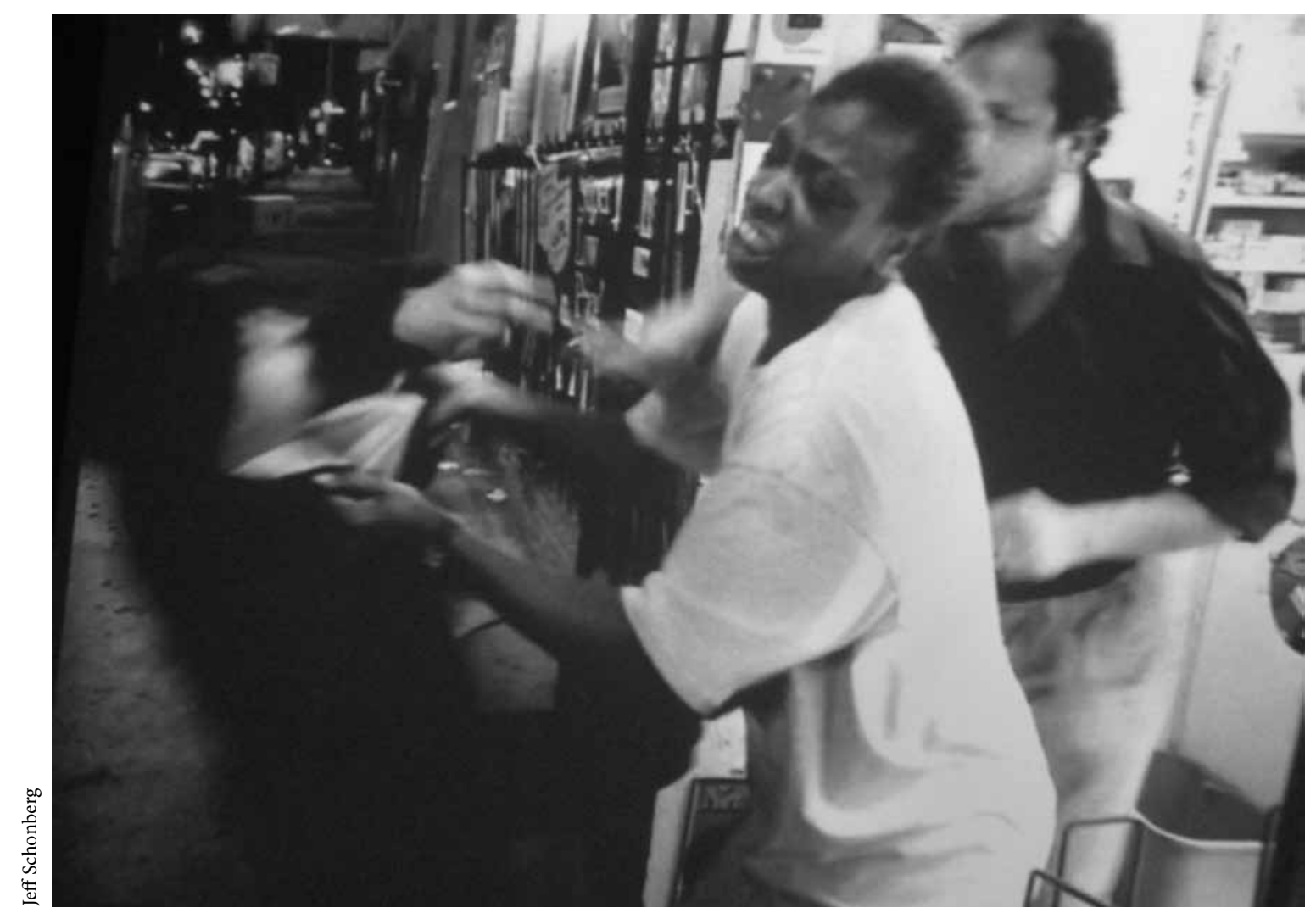

Foto presentada por Bourgois en la exposición sobre su trabajo en East Harlem. La violencia es un acontecimiento común en la cotidianidad de ese ghetto, 2004. 
de entrar en un barrio donde la gente es asesinada cotidianamente, las condiciones generales de vida son adversas y tener la decisión de poder salir, eso es algo trágico. Entonces, hacer la etnografía para mí es una manera de dar testimonio. También de sentirme útil al apreciar que las vidas sufridas de la gente que comparte el tiempo conmigo en la realización de la etnografía puedan tener importancia al representar el sufrimiento de un grupo de personas.

JAMC: Retomando la investigación En busca de respeto... señalabas en un pasaje: "gran parte de la tensión analítica que atraviesa el libro gira en torno al modo en que los individuos se enfrentan a las fuerzas que los oprimen". ${ }^{12}$ Siguiendo tal perspectiva, ¿otorgas importancia a las fuerzas estructurales?

PB: Para mí ésa es la tarea, en el sentido de no reproducir de manera más eficaz el trabajo de un periodista que realiza un trabajo de muy corto tiempo. Además, tiende a entrar y salir de manera rápida y no se ocupa suficientemente de la labor analítica. Aunque algunos trabajos periodísticos son buenos, en su mayoría son descripciones sin análisis. Por consiguiente, el análisis es el reto, ya que otorga un valor a la descripción. Al hacer un análisis en el trabajo de tipo etnográfico no se pueden perder de vista las interacciones, los actos y las palabras que pueden revelar cosas importantes, como fuerzas estructurales y formas de poder.

JAMC: A pesar de las condiciones desfavorables $y$ difíciles de vivir en East Harlem, señalabas que las personas tenían un potencial creativo y artístico, e incluso afirmabas: "ni la política pública ni las ciencias sociales se han sumado a las artes en su celebración de la vida en East Harlem y de sus habitantes" [le acerco el texto en la página de la que extraje la cita]. ${ }^{13}$

PB: [Lee con detenimiento] Creo que estaba hablando de lo increíblemente creativo del arte popular, la literatura y la música que han surgido en un

${ }^{12}$ Véase Bourgois (2010: 81).

${ }^{13}$ Véase Bourgois (2010: 91). barrio como Harlem, que es tan despreciado y marginado, motivos por los que debería ser un desierto artístico. Al contrario, es una olla de presión para producir. Puede argumentarse, por ejemplo, que Harlem y South Bronx fueron la cuna del hip hop e incluso antes, el jazz surgió del Harlem Central. Existe una literatura autobiográfica de sobrevivientes - exmaleantes- de Harlem que creó unas narraciones testimoniales que son muy latinoamericanas, aunque escritas en inglés por puertorriqueño. Estas literaturas narran las condiciones difíciles de vivir en Harlem, representando sus vidas como la experiencia de una generación. También se encuentran otras formas artísticas, como el graffiti, muy vinculado con el hip hop. Por eso decía en ese momento ${ }^{14}$ que la mayoría de los análisis de las ciencias sociales sobre Harlem no incluían esas expresiones creativas. Por otra parte, había teorías que estereotipaban de manera negativa la cultura popular. Luego las políticas públicas —en la década de 1950 - dirigidas a combatir la pobreza destruyeron el barrio para construir viviendas. El resultado fue un horror, debido a que disolvieron el tejido social al colocar a la gente en altos edificios donde nadie se conoce y no hay control social.

JAMC: En la presentación titulada "La furia en el ghetto estadounidense" que leíste en la Jornada sobre un estudio que desarrollas con un grupo de investigadores en un ghetto de Filadelfia expusiste fotografías de los sujetos, actividades y espacios del ghetto. Algunas fotografías llaman la atención, como las que muestran una especie de espacios sacralizados por las muertes violentas. ¿Qué representan esos espacios sacralizados en la calle?

PB: Es interesante, porque esa presentación la realicé en diferentes países antes de Venezuela y me preguntaron sobre esos altares. Realmente no había pensado en su significación. A partir de las preguntas es que empiezo a pensar en eso con el colectivo

\footnotetext{
${ }^{14}$ Hace aproximadamente 17 años de la primera publicación
} del libro. 


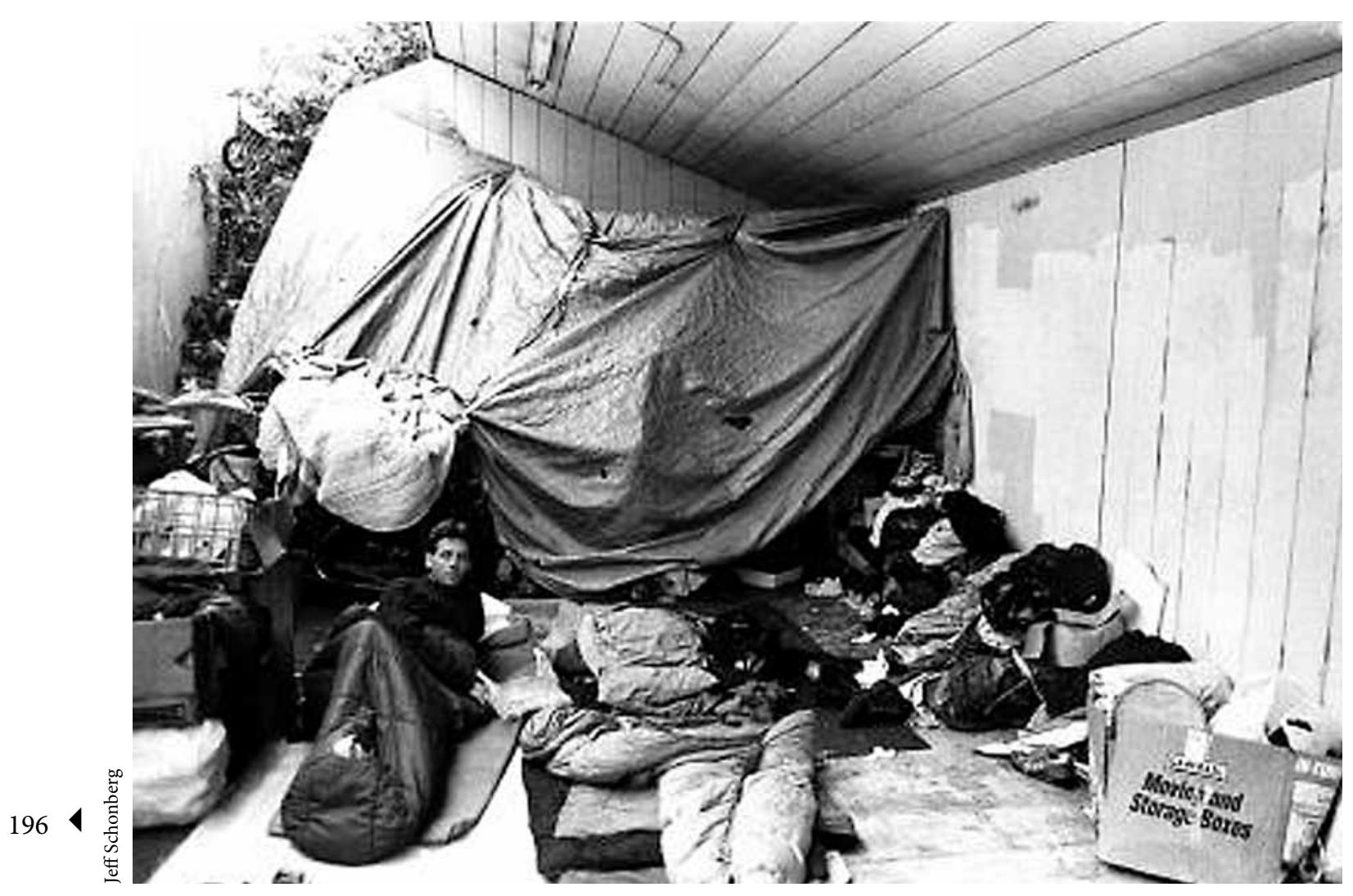

Foto realizada durante el trabajo de Burgois para Righteous Dopefiend, durante el que convivió con adictos a la heroína y al crack, 2009.

de trabajo. Ciertamente hay algo que analizar ahí. Por un lado es una forma de arte que ha surgido de los enfrentamientos cotidianos entre la misma gente que vive en el ghetto. Cada vez que ocurre un asesinato contratan a alguien para hacer un graffiti en el lugar. También las madres, esposas e hijos del asesinado colocan cosas personales del difunto. Hacen un altar y eso humaniza a la persona asesinada. Entre los objetos que colocan, los principales son los peluches favoritos de su infancia y fotos de graduación de primaria. Eso golpea la sensibilidad cuando se observa la pérdida de vida y humanidad de esas personas que estaban frecuentemente sumergidas en la violencia. Tales altares son colocados en el sitio donde fue asesinado y a veces duran mucho tiempo. En estos espacios, por una parte, hay una pintura que es estilo graffiti con el rostro del asesinado, y cerca de la pintura se colocan los objetos personales configurando un altar. A veces es una pintura inmensa realizada en la fachada de un edificio y abajo el altar con esos objetos que sus seres queridos colocan. Luego vuelven a los meses o al año para poner objetos nuevos. Un aspecto significativo de esas expresiones es que visibilizan esencialmente los pequeños genocidios invisibles de toda una generación de jóvenes pobres puertorriqueños, aunque ocurren de igual manera en los barrios afroestadounidenses. Esto ha surgido como una forma de arte y una visibilización de algo que la sociedad no toma en serio, que es la pérdida de vida por acciones violentas al interior de los barrios. En la actualidad son cada vez más reconocidos por la gente que vive en los ghettos, hasta convertirse en una forma de expresar el dolor. 


\section{Referencias bibliográficas}

Bell Lemus, Gustavo, 2002, "Presentación”, en Orlando Fals Borda, El presidente Nieto: historia doble de la Costa, t. 1, Ancora, Bogotá.

Bourgois, Philippe, 2009a, Treinta años de retrospectiva etnográfica sobre la violencia en las Américas en Guatemala: violencias desbordadas, Universidad de Córdoba, Córdoba.

2009b, Righteous Dopefiend, University of California Press, Berkeley.

,2010, En busca de respeto: vendiendo crack en Harlem, Siglo XXI, Buenos Aires.

Clifford, James, 2008, Itinerarios transculturales, Gedisa, Barcelona.

Fals Borda, Orlando, 2002a, El presidente Nieto: historia doble de la costa, t. 2, Ancora Editores, Bogotá. 2002b, "Sociología e investigación-acción participativa”, en El socialismo raizal y la Gran Colombia bolivariana, Fundación Editorial el Perro y la Rana, Caracas.

Moreno Olmedo, Alejandro et al., 1998, Historia de vida de Felicia Valera, Fondo Editorial de la Comisión Nacional de Investigación Científica y Tecnológica, Caracas. , 2008a, El aro y la trama. Episteme, modernidad y pueblo, Convivium Press, Florida.

, 2008b, "Los espacios de la violencia", en Yanett Segovia y Beatriz Nates (comps.), Territorios, identidades y violencias, Universidad de los Andes, Mérida.

et al., 2009, Y salimos a matar gente. Investigación sobre el delincuente venezolano violento de origen popular, vols. I y II, Plasarte, C. A., Caracas.

Sissa, Giulia, 2000, El placer y el mal. Filosofía de la droga, Península, Barcelona. 